\title{
Low-Cost CSI Using Forensic GPR, 3D Reconstruction, and GIS
}

\author{
Pier Matteo Barone ${ }^{1,2,3^{*}} \mathbb{C}$, Rosa Maria Di Maggio² \\ ${ }^{1}$ Archaeology and Classics Program, American University of Rome, Rome, Italy \\ ${ }^{2}$ Geoscienze Forensi Italia ${ }^{\circledR}$-Forensic Geoscience Italy, Rome, Italy \\ ${ }^{3}$ AcISF-Accademia Italiana di Scienze Forensi, Reggio Emilia, Italy \\ Email: *p.barone@aur.edu
}

How to cite this paper: Barone, P.M. and Di Maggio, R.M. (2019) Low-Cost CSI Using Forensic GPR, 3D Reconstruction, and GIS. Journal of Geographic Information System, 11, 493-499.

https://doi.org/10.4236/jgis.2019.115030

Received: August 9, 2019

Accepted: September 24, 2019

Published: September 27, 2019

Copyright (c) 2019 by author(s) and Scientific Research Publishing Inc. This work is licensed under the Creative Commons Attribution International License (CC BY 4.0).

http://creativecommons.org/licenses/by/4.0/ cc) (i) Open Access

\begin{abstract}
At a time in which several law enforcement agencies all around the world are facing severe expenditure reviews, the increasing use of low-cost solutions during crime scene investigations (CSI) can be a sustainable solution without being detracting from a scientific and rigorous forensic approach. Recently, some private companies are trying to satisfy the growing needs of the police to have cheaper and faster techniques to survey crime scenes and to obtain results with scientifically high-level outputs, more or less comparable with similar outputs from more expensive instruments. This paper reported results from a crime scene in which a low-cost GPR instrument, a free 3D photogrammetry software, and an open-source geographical information system (GIS) were deployed. The collection, processing, and analyses of these data will provide a very promising starting point for future low-cost and professional applications.
\end{abstract}

\section{Keywords}

GPR, CSI, Forensic Geoscience, 3D Reconstruction, GIS

\section{Introduction}

Because laws and practices vary among jurisdictions, comparing crimes between and even within countries can be difficult: typically, only violent deaths (homicides or manslaughters) can be reliably compared, due to consistent and high reporting and relatively clear definition [1].

Forensic science is a vital instrument for the detection of such crimes and the dispensation of justice. Private and public forensic science services play a critical role in the delivery of forensic services to the criminal justice system and have 
established themselves as references in forensic science [2].

Nowadays, the need for better management of the technology transfer process is beyond doubt, for facilitating exploitation of academic research, with potential for application to crime prevention and detection technologies.

Although it is accepted that flaws in expert evidence are unlikely to have led, in isolation, to a significant number of miscarriages of justice, it is impossible to determine the number of cases adversely affected by the conduct of an expert, or the handling of expert evidence in court. Where miscarriages of justice have arisen in association with problems in expert evidence, it reflects a system failure. Various measures are necessary to improve the handling of expert evidence [1] [2].

The number of forensic science courses available at the university level everywhere has increased dramatically over the last five/ten years. Various witnesses reported that the expansion in provision of forensic science degrees "does not reflect the limited employment prospects in forensic science, nor is it in response to employers in the sector". Rather, the growth was a result of student interest in forensic science, which was, at least in part, stimulated by television dramas featuring forensic scientists and high-profile coverage of forensic science in books and by the media [3].

[3] and [4] reported that the real problem was how to get an understanding of the sophistication level of some scientific techniques or investigative values at ground level, in the average police force. Moreover, there is no model for good practice demonstrating that there is still a great deal of variation in performance of different forces [3] [4]. [2], for example, highlighted the fact that "many forces still have a great deal of difficulty in managing the process of turning identifications into detections and this is rooted in a paucity of quality performance information".

In recent years, the spotlight has fallen on the use of expert evidence in court, the purpose of which is to provide the court with information based on scientific results, the interpretation of which is outside the experience and knowledge of a judge and jury. It is the court's responsibility to decide whether there is a need for expert evidence and also to establish the competence of the expert witness. If the expert evidence is clear and not contradicted by any other evidence, the jury should accept it. If the evidence is not clear, or there is evidence which contradicts the expert's opinion, the jury may reject it [2].

Forensic investigations are increasingly utilizing advanced technology, especially in investigations seeking hidden/buried evidence. The Ground Penetrating Radar (GPR) is a major instrument used by law enforcement and investigators to detect hidden sites such as bricks or concrete walls, wooden floors, or secret graves and buried objects. It can be used to detect anomalies of the soil, so that the evidence itself is difficult to deal with, although digging holes can point the right researchers in the right direction. It is possible to eliminate suspicious areas, saving time and money. In addition to finding positive evidence, GPR is a useful tool for narrowing down or limiting areas of interest, to reduce costly and 
disruptive excavation [5] [6] [7] [8].

Moreover, other modern and highly technological tools frequently used in forensic investigations are the $3 \mathrm{D}$ reconstructions of the CS and the creation of spatial databases using GIS platforms. These approaches are frequently very expensive in respect of both the hardware and software and not all the law enforcement agencies have the money to include such technologies in the investigations [9] [10]. In particular, several police agencies are facing expenditure review plans due to the global economic crisis and are forced to cut utilization of costly technologies and having to resort to cheaper solutions, sometimes at the cost of the scientific level of the forensic investigation [11].

The aim of this paper is to provide preliminary, alternative, and cheaper solutions to law enforcement agencies, with particular regard to non-destructive evaluation of a CS, without sacrificing the scientific aspect.

\section{Materials and Methods}

\subsection{GPR}

Almost all the companies producing GPR systems prefer to create a product that can be adaptable to any solution and problem. This is the main reason why GPR systems are very flexible, all-in-one, and competitive. However, often, GPR costs are very high due to these different tools embedded in such systems.

In this paper, we will use a GPR system specifically designed to meet forensic needs in terms of both functionality and economic affordability: the FINDAR by Sensors \& Software, Inc. (https://www.sensoft.ca/products/findar/overview/). This system is equipped with a bistatic $500 \mathrm{MHz}$ antennas with an internal GPS. Both radargrams and two adjacent depth slices $(0.25 \mathrm{~m}$ interlined) are collected in an area of $10 \times 5 \mathrm{~m}$.

This choice was made for two main reasons: 1) economically, it is the cheaper GPR system available for forensic purposes, and 2) it is particularly handy and comprehensible.

\subsection{D Reconstruction}

The majority of the costs during a survey is incurred on photo collections and photogrammetry. To avoid such expenses, in this work, a 100-Euro commercial smartphone camera (Motorola Moto G (5S) Plus) and a free online software (3DF Zephyr Free version 4: https://www.3dflow.net/3df-zephyr-free/) were used. Following the online instructions of the software, the CS photos (numbering 28) were collected in less than 5 minutes, and their processing took no more than 20 minutes, producing 1) a sparse points cloud, 2) a dense points cloud, 3) a mesh, and 4) a texture mesh of every single phase before, during, and after the exhumation of the wrapped body.

\subsection{GIS}

During forensic investigations, the GIS platform allows the georeference to store 
all the data acquired during previous measurements. Generally, the software used for such operations is very expensive and not always affordable. The software used is one of the most popular and downloaded free software: QGIS (https://www.qgis.org/en/site/). In this case, just GPR data and 3D reconstructions were collected and spatially analyzed, to obtain a sort of general overview of different evidences collected at the CS, to retrieve and present efficiently in a courtroom. Normally, it is possible to upload various evidences (organic, geological, archaeological, and taphonomic samples, footprints, etc.) from the same CS.

\section{Results}

Thanks to a very high level of intelligence, the suspected area was limited to a rectangle of $10 \times 5 \mathrm{~m}$, in which GPR measurements were carried out. Based on both radargrams and depth slices, it was possible to notice a few anomalies related to some typical forensic targets. Figure 1(a) shows two radargrams acquired at the CS, in which a ringing effect is visible a few centimeters below the surface, probably due to a metal object buried in the shallow subsurface. Figure 1(b) shows a typical GPR anomaly due to a "cut" in the soil related to the pit created possibly by the culprit to hide a body or an object (i.e., two later hyperbolic events and a central sub-horizontal anomaly) [5] [6] [7] [8] [9].

Figure 2 shows the depth slices of the two adjacent areas. In particular, Figure 2(a) illustrates the anomaly related to the radargram in Figure 1(a), at the depth of $0.2 \mathrm{~m}$ approximately, while Figure 2(b) shows the anomaly noted in Figure 1 (b), highlighting the limit of the buried pit at a depth of about $0.4 \mathrm{~m}$ with a dimension of $2 \times 1 \mathrm{~m}$. Based on both the geometries and the dimensions of these

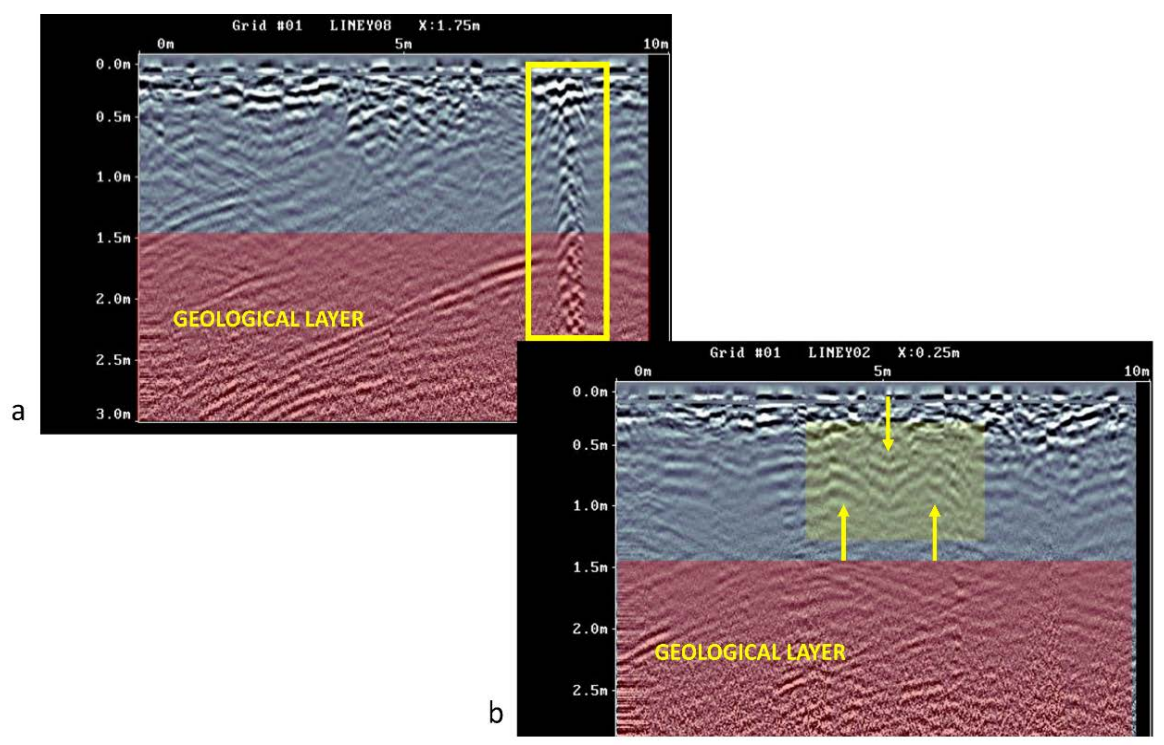

Figure 1. Radargrams acquired at the CS; in (a) is highlighted the ringing effect due to a probable buried metal object. (b) emphasizes the typical GPR effect due to a "cut" in the soil. 


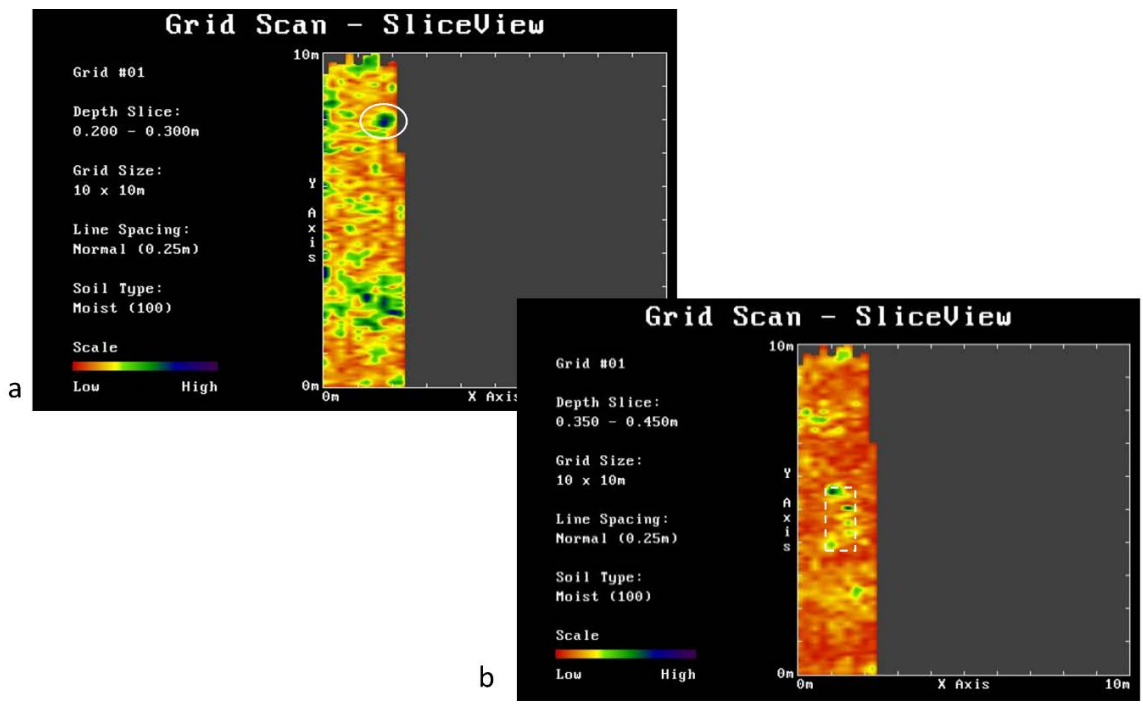

Figure 2. The figure shows the depth slices of the two adjacent areas. In particular, (a) illustrates the anomaly related to the radargram in Figure 1(a), at the depth of $0.2 \mathrm{~m}$ approximately, while (b) shows the anomaly noted in Figure 1(b), highlighting the limit of the buried pit at a depth of about $0.4 \mathrm{~m}$ with a dimension of $2 \times 1 \mathrm{~m}$.

two targets, it was possible to deduce the presence of a metallic weapon (i.e., short gun) and a human burial. Subsequent exhumation confirmed these hypotheses.

Figure 3 displays the 3D elaboration of the CS, in which is visible one of the several exhumation phases (the human burial identification). The high level of resolution and accuracy of the $3 \mathrm{D}$ data recorded and processed can be seen.

Finally, Figure 4 is a screenshot of the GIS obtained from the above collected, georeferenced, and stored data, in order to create a user-friendly spatial database to be used by law enforcement agency in the courtroom, and by future investigators in the contingency of a cold case.

The high level of accuracy of these results demonstrates the possibility of collecting and analyzing data even with cheaper instruments without sacrificing scientific aspects. This forensic investigation reaped enormous benefits from these handy, economic, and precise results.

\section{Discussion and Final Remarks}

Forensic science is now central to the detection and deterrence of crime, conviction of the guilty and exculpation of the innocent. Moreover, the significance of forensic science to the criminal justice system can be expected to increase in the years to come.

The three core aims of a forensic strategy should be as follows: 1) to establish priorities for current and future science and technology applications and research; 2) to coordinate the development and implementation of technology between users and suppliers, to ensure a coherent and effective process; 3 ) to implement processes for future scanning to ensure that the police service can 


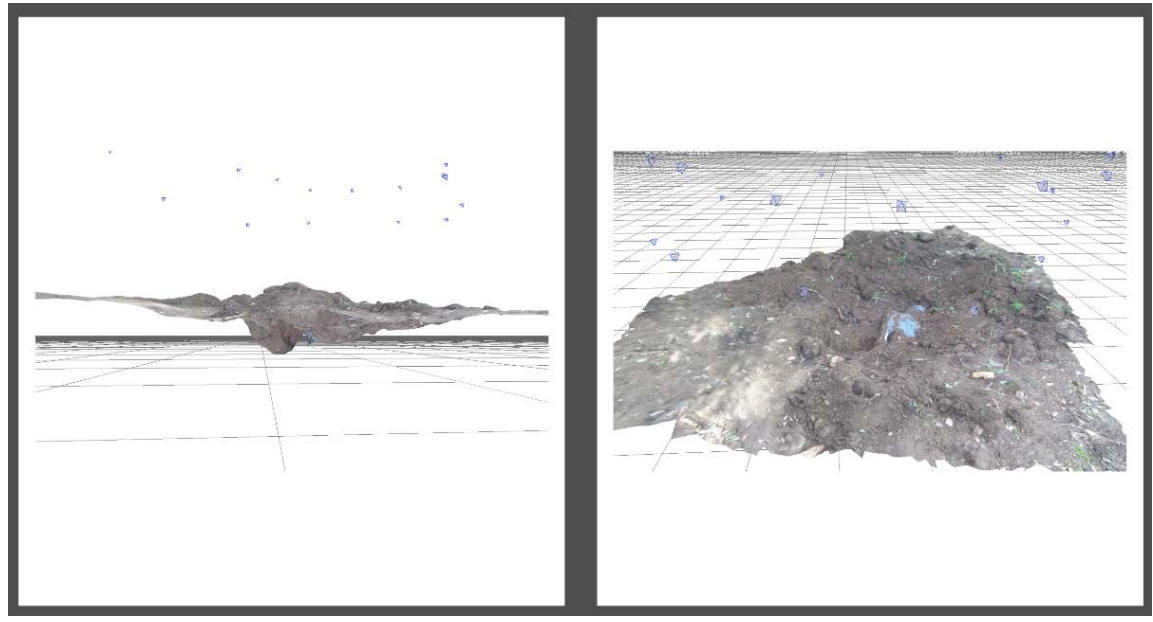

Figure 3. High-resolution 3D acquisition of one of the several exhumation phases (the burial identification of the wrapped body). Note the small blue squares from various camera angles.

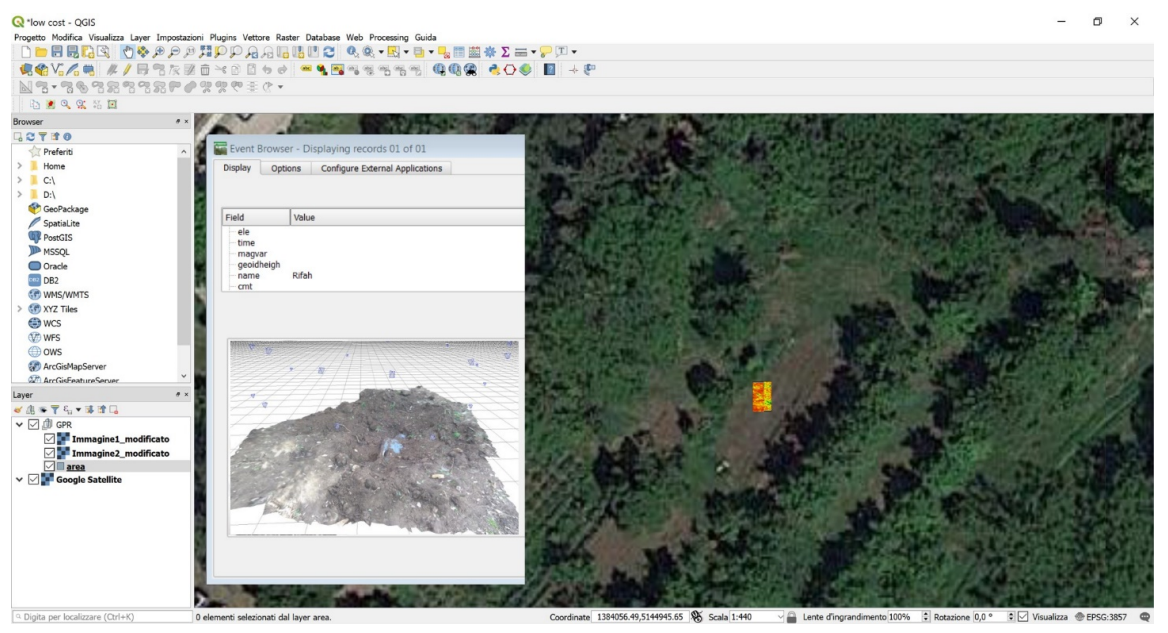

Figure 4. The GIS process of all the above-mentioned data creating only one forensic database.

exploit new technology at the earliest opportunity and is prepared for new technology-based threats [2].

Because the correct procedure to follow during non-destructive forensic investigations is clear and established [12] [13], in case the economic situation does not allow requisite expenditure on appropriate forensic scientific equipment, this need not be a deterrent in the administration of justice. It is necessary to find solutions to suit all pockets and budgets, without compromising on the rigorous scientific method.

\section{Conclusion}

In conclusion, the aim of this paper was exactly to initiate a discussion in this regard and to kindle interest on the topic, for the sake of not only justice but the whole civil society. 


\section{Conflicts of Interest}

The authors declare no conflicts of interest regarding the publication of this paper.

\section{References}

[1] Van Dijk, J.J.M. (2008) The World of Crime; Breaking the Silence on Problems of Crime, Justice and Development. Sage Publications, Thousand Oaks. https://doi.org/10.4135/9781483329789

[2] House of Commons (2005) Forensic Science on Trial. Science and Technology Committee, London, UK, 1-98.

[3] Fraser, J. and Williams, R. (2009) Handbook of Forensic Science. Willan, London.

[4] Fraser, J. (2010) Forensic Science: A Very Short Introduction. OUP, Oxford. https://doi.org/10.1093/actrade/9780199558056.001.0001

[5] Barone, P.M. (2016) Understanding Buried Anomalies: A Practical Guide to GPR. LAP Lambert Academic Publishers, Saarbrücken.

[6] Barone, P.M. and Groen, M. (2018) Multidisciplinary Approaches to Forensic Archaelology. Topics Discussed during the European Meetings on Forensic Archaeology (EMFA), Soil Forensics Series, Springer International Publishing, Berlin. https://doi.org/10.1007/978-3-319-94397-8

[7] Sturdy Colls, C. (2015) Holocaust Archaeologies: Approaches and Future Directions. Springer, Berlin. https://doi.org/10.1007/978-3-319-10641-0

[8] Di Maggio, R.M. and Barone, P.M. (2017) Geoscientists at Crime Scenes. A Companion to Forensic Geoscience, Soil Forensics Series, Springer International Publishing, Berlin. https://doi.org/10.1007/978-3-319-58048-7

[9] Barone, P.M., Di Maggio, R.M. and Ferrara, C. (2015) Not Necessarily Buried Bodies: Forensic GPR Investigations from Criminal to Civil Justice. Proceedings of the 8th International Workshop on Advanced Ground Penetrating Radar, Florence, 7-10 July 2015, 1-4. https://doi.org/10.1109/IWAGPR.2015.7292681

[10] Di Maggio, R.M., Donnelly, L.J., Al Nuaimi, K.S., Barone, P.M., et al. (2017) Global Developments in Forensic Geology. Episodes, 40, 120-131.

https://doi.org/10.18814/epiiugs/2017/v40i2/017014

[11] Agbenyega, J. (2011) Forensic Research Funding Cuts. Materials Today, 14, 1-2. https://doi.org/10.1016/S1369-7021(11)70001-3

[12] Barone, P.M. and Di Maggio, R.M. (2019) Dealing with Different Forensic Targets: Geoscientists at Crime Scenes. Geological Society, London, Special Publications, 492. https://doi.org/10.1144/SP492-2017-274

[13] Ruffell, A. and McKinley, J. (2008) Geoforensic. John Wiley \& Sons Ltd., Hoboken. https://doi.org/10.1002/9780470758854 